\title{
Effects of Adulteration on Diesel Oil with Kerosene Fuel in Ghana
}

\author{
${ }^{1,2,3}$ BOADU, KO \\ ${ }^{I}$ World Bank Africa Centre of Excellence, Centre for Oil Fields Chemicals, Institute of Petroleum Studies, University of Port Harcourt, \\ Nigeria \\ ${ }^{2}$ Department of Chemistry, University of Cape Coast, Cape Coast, Ghana \\ ${ }^{3}$ Department of Chemical Engineering, University of Port Harcourt, Port Harcourt, Nigeria \\ *Corresponding AuthorEmail: koboadu@ucc.edu.gh, boadu.kwasi@aceuniport.org
}

\begin{abstract}
This research was carried out to estimate the proportional mixtures of diesel and kerosene that easily shows the incidence of fuel adulteration. Two samples (kerosene and diesel) were obtained from a base stock at Tema Oil Refinery and the purity for both the kerosene and diesel were ensured by testing their density, kinematic viscosity, distillation and flash point. The values obtained for these parameters after the analyses carried out are density at $15^{\circ} \mathrm{C}$ falls within $816-850 \mathrm{kgm}^{3}$; the flashpoint was found to be within $48-73^{\circ} \mathrm{C}$; distillation at $360{ }^{\circ} \mathrm{C}$ were in the range of $96-98^{\circ} \mathrm{C}$ and kinematic viscosity at $37.8^{\circ} \mathrm{C}$ were also in the range $1.5-3.5 \mathrm{~mm}^{2} / \mathrm{s}$. The parameters analysed are good indicators in the assessment of the extent to which diesel fuel can be adulterated by kerosene. The above parameters were analysed using both standard American Society for Testing and Materials (ASTM) methods and Statistical Package for the Social Sciences (SPSS) version 23 statistical tools. The values obtained from the experiments conform to respective standards of United States Environmental Protection Agency (USEPA) regulations at 40CFR 79, 2017 and other literature values. The correlation coefficient $\left(\mathrm{R}^{2}\right)$ obtained after statistical analyses are 0.9984 for flash point, 0.9985 for density, 0.9405 for distillation and 0.9962 for kinematic viscosity. Also, analyses of variance (ANOVA) was $\operatorname{Pr}>\mathrm{F}<0.0001$ for all the parameters. However, the F calculated for various parameters are 669.3500 for flash point, 693.7294 for density, 16.6000 for distillation and 272.3459 for kinematic viscosity. This shows that the various parameters play a significant role in the adulteration of diesel fuel.
\end{abstract}

DOI: https://dx.doi.org/10.4314/jasem.v23i7.1

Copyright: Copyright (C) 2019 Boadu. This is an open access article distributed under the Creative Commons Attribution License (CCL), which permits unrestricted use, distribution, and reproduction in any medium, provided the original work is properly cited.

Dates: Received: 12 June 2019; Revised: 16 July 2019; Accepted 25 July 2019

Keywords: Diesel, kerosene, adulteration, density, kinematic viscosity, flash point, distillation

Diesel fuel is responsible for approximately $47 \%$ of all fuel consumed in road transportation in Ghana. As a result of this high consumption, fuel adulteration has increased and fraudsters have used irregular substances, such as kerosene and residual and vegetable oils, which have good miscibility with the fuel making it difficult to detect the fraud. Adulteration causes irreparable damage to engines, such as sudden failure, difficulty in starting, increased fuel consumption, low fuel spraying rate in the combustion chamber, and increased emissions of particulate matter [Danyelle et al., 2019]. The National Petroleum Authority (NPA) of Ghana has plans to forestall adulteration of diesel fuel. There have been reports of fuel adulteration by petroleum retailers, especially oil marketing companies or fuel service station operators mixing premium quality refined diesel fuel which government had subsidized with kerosene and premixed fuel meant for fishermen in the Ghanaian society. Kerosene and pre-mixed fuel are cheaper than diesel fuel in Ghana. Recently, pre-mixed fuel in Ghana was coloured to put a stop to that practice, and the NPA has hinted that it would soon colour kerosene as well as introduce a new marker system which is used globally to prevent adulteration of transported fuels in Ghana. This new marker will help guarantee that subsidized kerosene and pre-mixed fuel currently diverted from the public distribution system can reach the target group (Wenming Yang et al. 2017). Adulteration of transport diesel fuels, which are currently a flourishing business in Ghana, leads to economic losses, deterioration of engines, failure of vehicle components and safety problems. Adulteration of fuel can also cause health problems directly in the form of increased emission of harmful gases that affects the quality of air (Yang et al., 2016). Currently, there is a lot of talk, discussions and debate on adulteration and contamination of petroleum products in Ghana in various media. This discourse has been characterized in some cases by the emotional outburst and pointing of fingers, and rightly so at the suspected culprits. And in some cases at state agencies that are supposed to have an oversight role in the petroleum industry (Henry Mensah-Brown, 2013). The cost of adulteration and contamination in terms of damage to fuel pumps, engines and other consumers of petroleum

*Corresponding AuthorEmail: koboadu@ucc.edu.gh,boadu.kwasi@aceuniport.org 
products are quite high. Adulteration is a conscious effort to contaminate petroleum products (Graham Hill and John Holman, 2000). The motive is usually driven by an increase in margins gain by petroleum retailers or oil marketing companies. Due to the gained incentive, this obnoxious practice is preferred to an art (USEPA regulations at 40CFR 79, 2017). Some of the arguments put forward in the debate on adulteration and contamination of petroleum products dwell on the perception that the gross margin allowed the fuel filling stations and the Oil Marketing Companies (OMCs) are relatively small, compared to the totality of various levies or duties that go to the government and its agencies. In the case of adulteration, the practice hinges around mixing of low-cost products with relatively high-cost products in order to sell the resultant mixture at a higher price for an illegal gain. Adulteration of diesel and other petroleum products is indulged primarily due to the significant price difference between these products and the adulterants. Financial incentives arising from differential taxes are generally the primary cause of fuel adulteration. There have been several independent studies conducted by private agency vis- a- vis the quality of diesel that gets dished out from the outlets to the ultimate consumer. Most developing countries' government has not yet established a monitoring regime and system of fines that can act as a strong deterrent to fuel adulteration (Jonah and Umar, 2004). There is a number of reasons for this, including poor governance, lack of political will power, lack of regulatory laws and enforcement, lack of awareness, weak regulatory agencies and shortage or even absence of technical staff and equipment to design and conduct periodic monitoring. The blending of kerosene with automotive diesel is generally practised by oil industry worldwide as a means of adjusting the low-temperature operability of the fuel. This practice is not harmful or detrimental to tailpipe emissions, provided the resulting fuel continues to meet engine manufacturer's specification (especially for viscosity and cetane number). However, high-level adulteration of low sulphur diesel fuel with high-level sulphur kerosene can cause the fuel to exceed the sulphur maximum (Kadir Gedik and Yasin Uzun, 2015; Kun Lin Tay et al 2016). The addition of heavier fuel oils to diesel is usually easy to detect because the resultant fuel will be darker than normal. Depending on the nature of these heavier fuel oils and the possible presence of additional polyaromatic Hydrocarbons(PAHs), there could be some increase in both exhaust polymethane(PM) and PAH emissions. The purpose of this research work is to estimate proportional mixtures of diesel and kerosene that easily shows the incidence of diesel fuel adulteration.

\section{MATERIALS AND METHOD}

Sample Collection: 4.5 litres of both diesel and kerosene were purchased from a base source (i.e. Tema Oil Refinery). The purity for both the kerosene and diesel were ensured by testing for their density, kinematic viscosity, distillation and flash point and compared their values obtained with respective standard literature and reference values.

Frequency of Sample Collection: The unadulterated diesel and kerosene were mixed in volume by volume proportions to obtain 21 different blends in the ratios of 100:0, 95:5, 90:10, 85:15, 80:20, 75:25, 70:30, 65:35, $60: 40,55: 45,50: 50,45: 55,40: 60,35: 65,30: 70,25: 75$, $20: 80,15: 85,10: 90,5: 95,0: 100$, diesel and kerosene respectively. The final volume of the prepared adulterant mixture for each proportion was $100 \mathrm{ml}$. The various mixers were shaken vigorously using the Stuart linear shaker model SSL2 with an amplitude of $20 \mathrm{~mm}$ and rotation speed of $20-250 \mathrm{rpm}$ to ensure effective mixing of the diesel and kerosene fuels prepared. The blending was done in pair; one pair of the blends were used for distillation analytical test which required high temperature. The other pair was used for the density, flashpoint, and kinematic viscosity analytical test methods. Hence, the sample size were $21 \times 4 \times 4=336$ in total. There were twenty-one (21) proportions of the prepared samples which were analysed four (4) times for each of the analytical test methods.

Proportional Mixtures of Diesel and Kerosene: With the aid of two separate $100 \mathrm{ml}$ measuring cylinder, the unadulterated diesel (100:0) and kerosene $(0: 100)$ were measured and transferred into separate sample bottles and covered. The subsequent ratios which were in the interval of $5 \mathrm{ml}$ each were also measured and blended well in sample bottles. Various standard literature methods or procedures were followed to determine the parameters under analyses. Also, the values obtained were analysed using the SPSS version 23 statistical method.

Density at $15^{\circ} \mathrm{C}$ (ASTM: D1298-04): This method was used to determine the density of the samples prepared. This test method covers the laboratory determination using a glass hydrometer, of the density, relative density (specific gravity), or API gravity of crude petroleum, petroleum products, or mixtures of petroleum and nonpetroleum products normally handled as liquids, and having a Reid vapour pressure of $101.325 \mathrm{kPa}$ or less. A calibrated hydrometer between the ranges of $800 \mathrm{~kg} / \mathrm{m}^{3}$ to $900 \mathrm{~kg} / \mathrm{m}^{3}$ and a calibrated thermometer was used. 
Distillation in ${ }^{\circ} \mathrm{C}$ (ASTM: D86-12): The samples prepared were determined using this method. This test method covers the atmospheric distillation of petroleum products using a laboratory batch distillation unit to determine quantitatively the boiling range characteristics of such products as light and middle distillates, automotive spark-ignition engine fuels with or without oxygenates, aviation gasoline, aviation turbine fuels, special petroleum spirits, naphtha, white spirits, kerosene, and Grade 1 and 2 burner fuels.

Flash Point in ${ }^{\circ} \mathrm{C}$ (ASTM: D93-2004): This method was used to determine the flash point of the various samples prepared. This test methods cover the determination of the flash point of petroleum products in the temperature range from $40^{\circ} \mathrm{C}$ to $360^{\circ} \mathrm{C}$ by a manual Pensky-Martins closed-cup apparatus or an automated Pensky-Martins closed-cup apparatus, and also the determination of biodiesel in the temperature range of $60^{\circ} \mathrm{C}$ to $190^{\circ} \mathrm{C}$ by an automated PenskyMartins closed-cup apparatus.

Kinematic Viscosity at $37.8^{\circ} \mathrm{C}$ (ASTM: D445-06): The samples prepared were analysed using this method to determine their Kinematic Viscosity. This test method specifies a procedure for the determination of the kinematic viscosity, $\mathrm{v}$, of liquid petroleum products, both transparent and opaque, by measuring the time for a volume of flow under gravity through a calibrated glass capillary viscometer. The dynamic viscosity, $\mathrm{y}$, can be obtained by multiplying the kinematic viscosity, $v$, by the density, $\rho$, of the liquid.

\section{RESULTS AND DISCUSSIONS}

The results are collected in tables 1,2 and 3. Also, the values obtained were analysed using the SPSS version 23 statistical method. The results obtained are then compared with standard values collected in UNE 590 (2013), USEPA regulations at 40CFR 79, (2017) and other research works investigated earlier on.

\begin{tabular}{|c|c|c|c|c|}
\hline $\begin{array}{l}\text { Proportion mixtures } \\
\text { of Diesel: Kerosene }\end{array}$ & $\begin{array}{l}\text { Mean Flash Point } \\
\pm \text { std }\left({ }^{\circ} \mathrm{C}\right)\end{array}$ & $\begin{array}{l}\text { Mean Density } \\
\pm \text { std }\left(\mathrm{kg} / \mathrm{m}^{3)}\right.\end{array}$ & $\begin{array}{l}\text { Mean Distillation } \\
\pm \text { std }\left({ }^{\circ} \mathrm{C}\right)\end{array}$ & $\begin{array}{l}\text { Mean Kin.Viscosity } \\
\pm \text { std }\left(\mathrm{mm}^{2} / \mathrm{s}\right)\end{array}$ \\
\hline $0: 100$ & $48.00 \pm 0.00$ & $816.00 \pm 0.00$ & $98.00 \pm 0.00$ & $1.50 \pm 0.00$ \\
\hline $5: 95$ & $47.50 \pm 0.71$ & $818.00 \pm 0.00$ & $96.50 \pm 0.71$ & $1.60 \pm 0.00$ \\
\hline $10: 90$ & $51.00 \pm 0.00$ & $819.50 \pm 0.71$ & $96.00 \pm 0.00$ & $1.70 \pm 0.00$ \\
\hline $15: 85$ & $51.00 \pm 0.00$ & $820.00 \pm 0.00$ & $96.00 \pm 0.00$ & $1.75 \pm 0.71$ \\
\hline $20: 80$ & $51.00 \pm 0.00$ & $821.5 \pm 0.71$ & $96.00 \pm 0.00$ & $1.90 \pm 0.00$ \\
\hline $25: 75$ & $51.00 \pm 0.00$ & $823.50 \pm 0.71$ & $96.00 \pm 0.00$ & $1.98 \pm 0.35$ \\
\hline $30: 70$ & $51.50 \pm 0.71$ & $825.50 \pm 0.71$ & $96.00 \pm 0.00$ & $2.05 \pm 0.71$ \\
\hline $35: 65$ & $52.00 \pm 0.00$ & $827.50 \pm 0.71$ & $96.00 \pm 0.00$ & $2.15 \pm 0.71$ \\
\hline $40: 60$ & $56.50 \pm 0.71$ & $829.50 \pm 0.71$ & $96.00 \pm 0.00$ & $2.28 \pm 0.35$ \\
\hline $45: 55$ & $57.00 \pm 0.00$ & $832.50 \pm 0.71$ & $96.00 \pm 0.00$ & $2.40 \pm 0.00$ \\
\hline $50: 50$ & $57.50 \pm 0.71$ & $834.50 \pm 0.71$ & $96.00 \pm 0.00$ & $2.55 \pm 0.71$ \\
\hline $55: 45$ & $58.00 \pm 0.00$ & $836.50 \pm 0.71$ & $96.00 \pm 0.00$ & $2.63 \pm 0.35$ \\
\hline $60: 40$ & $58.00 \pm 0.00$ & $838.50 \pm 0.71$ & $96.00 \pm 0.00$ & $2.70 \pm 0.00$ \\
\hline $65: 35$ & $58.50 \pm 0.71$ & $840.50 \pm 0.71$ & $96.00 \pm 0.00$ & $2.83 \pm 0.35$ \\
\hline $70: 30$ & $60.00 \pm 0.00$ & $842.50 \pm 0.71$ & $96.00 \pm 0.00$ & $2.93 \pm 0.35$ \\
\hline $75: 25$ & $60.50 \pm 0.71$ & $844.50 \pm 0.71$ & $96.00 \pm 0.00$ & $3.00 \pm 0.00$ \\
\hline $80: 20$ & $63.50 \pm 0.71$ & $846.50 \pm 0.71$ & $96.00 \pm 0.00$ & $3.00 \pm 0.00$ \\
\hline $85: 15$ & $70.50 \pm 0.71$ & $848.50 \pm 0.71$ & $96.00 \pm 0.00$ & $3.05 \pm 0.71$ \\
\hline $90: 10$ & $71.00 \pm 0.00$ & $850.00 \pm 0.00$ & $96.00 \pm 0.00$ & $3.05 \pm 0.71$ \\
\hline $95: 5$ & $72.00 \pm 0.00$ & $850.50 \pm 0.71$ & $96.00 \pm 0.00$ & $3.05 \pm 0.71$ \\
\hline 100:0 & $73.00 \pm 0.00$ & $850.00 \pm 0.71$ & $96.00 \pm 0.00$ & $3.05 \pm 0.71$ \\
\hline \multicolumn{5}{|c|}{$\begin{array}{c}\text { able 2: Correlation Co-efficient of various parameters } \\
\text { Flash Point } \quad \text { Density }\end{array}$} \\
\hline \multicolumn{2}{|c|}{ Correlation Co-efficient $\left(\mathrm{R}^{2}\right)$} & 984 & 0.9405 & 0.9962 \\
\hline
\end{tabular}

Density at $15{ }^{\circ} \mathrm{C}$ : The density is a very important parameter, since the injection systems, pumps and injectors must deliver the amount of diesel precisely adjusted to provide proper combustion (Dzida and Prusakiewicz, 2008). The density is related to the type of raw material and the purification steps (Predojevic, 2008).From the ASTM: D1298-04 test conducted to ascertain the density of the various mixtures of diesel to kerosene at $15^{\circ} \mathrm{C}$ as indicated in table 1 and plotted on graph 2 , it shows that the density of the mixture 100:0 (\%) (Unadulterated diesel) was $850 \mathrm{~kg} / \mathrm{m}^{3}$. This value was maintained up to a mixture of $90: 10(\%)$ (Diesel: kerosene). From the mixture of 85:15 (\%), the density obtained was $848 \mathrm{~kg} / \mathrm{m}^{3}$. The density of the various mixtures started to reduce by $2 \mathrm{~kg} / \mathrm{m}^{3}$ as shown in table 1 and plotted on graph 2 . The density of mixtures became stable at 40:60 (\%) mixture with a value of $830 \mathrm{~kg} / \mathrm{m}^{3}$. Irrespective of the level of adulteration performed within the mixtures range of 95:5 to 40:60 (\%), they all met the Standard of density required in diesel fuel which is in the range of 830-880 $\mathrm{kg} / \mathrm{m}^{3}$ (UNE-EN ISO 3838,2004; Maceiras et al., 
2017). However, the adulterated diesel lost its usefulness completely at the mixtures range of 35:65 to $0: 100(\%)$ (Diesel: kerosene). Within these ranges, the density of adulterated diesel fuels was far from the recommended range of $830-880 \mathrm{~kg} / \mathrm{m}^{3}$. The observations from the experiment suggested that density was within the prescribed range immaterial of diesel-adulteration level with kerosene (Table 1). The presence of kerosene did not alter the density of diesel appreciably and hence density test for adulteration with kerosene is not useful. The observed variation in opacity with different proportions of adulterant although not sharp, showed a decreasing trend with increasing adulterant presence in diesel (Maceiras et al., 2017). However, the correlation coefficient $\left(\mathrm{R}^{2}\right)$ was 0.9985 and analyses of variance gave a $\operatorname{Pr}>\mathrm{F}$ $<0.0001$. The above values obtained were significant and it shows that density can be a determinant factor in diesel fuel adulteration.

Table 3: Analyses of variance of various parameters

\begin{tabular}{|c|c|c|c|c|c|}
\hline \multicolumn{6}{|l|}{ Flash Point } \\
\hline Source & DF & Sum of squares & Mean squares & $\mathrm{F}$ & $\operatorname{Pr}>\mathrm{F}$ \\
\hline Model & 20 & 2549.9048 & 127.495 & 669.35 & $<0.0001$ \\
\hline Error & 21 & 4.0000 & 0.1905 & & \\
\hline Corrected Total & 41 & 2553.9048 & & & \\
\hline \multicolumn{6}{|c|}{ Computed against model $Y=\operatorname{Mean}(Y)$} \\
\hline \multicolumn{6}{|c|}{ 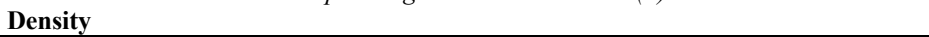 } \\
\hline Source & DF & Sum of squares & Mean squares & $\mathrm{F}$ & $\operatorname{Pr}>\mathrm{F}$ \\
\hline Model & 20 & 5615.9048 & 280.7952 & 693.7294 & $<0.0001$ \\
\hline Error & 21 & 8.5000 & 0.4048 & & \\
\hline Corrected Total & 41 & 5624.4048 & & & \\
\hline \multicolumn{6}{|c|}{ Computed against model $Y=\operatorname{Mean}(Y)$} \\
\hline \multicolumn{6}{|l|}{ Distillation } \\
\hline Source & DF & Sum of squares & Mean squares & $\mathrm{F}$ & $\operatorname{Pr}>\mathrm{F}$ \\
\hline Model & 20 & 7.9048 & 0.3952 & 16.6000 & $<0.0001$ \\
\hline Error & 21 & 0.5000 & 0.0238 & & \\
\hline Corrected Total & 41 & 8.4048 & & & \\
\hline \multirow{2}{*}{\multicolumn{6}{|c|}{ Computed against model $Y=\operatorname{Mean}(Y)$}} \\
\hline & & & & & \\
\hline Source & $\mathrm{DF}$ & Sum of squares & Mean squares & $\mathrm{F}$ & $\operatorname{Pr}>\mathrm{F}$ \\
\hline Model & 20 & 11.9962 & 0.5998 & 272.3459 & $<0.0001$ \\
\hline Error & 21 & 0.0463 & 0.0022 & & \\
\hline Corrected Total & 41 & 12.0424 & & & \\
\hline
\end{tabular}

Distillation at $360{ }^{\circ} \mathrm{C}$ : The distillation temperatures for all the adulterated mixtures were recorded in table 1. As seen in the graph. 3, it can be observed from the boiling point behaviour of the samples during distillation that adulterated mixtures have lower boiling points than the unadulterated diesel. This fact occurs due to the compositional difference between the diesel and the kerosene (Gambarra et al, 2009) for identifying adulteration since changes in the curve profiles occur when the chemical composition of the fuel changes. However, this technique has several disadvantages, such as the high analysis time and the damage that residual oil can inflict on the equipment. Also, the correlation coefficient $\left(\mathrm{R}^{2}\right)$ of 0.9405 and analyses of variance value of $\operatorname{Pr}>\mathrm{F}<0.0001$, distillation can be an appropriate parameter for assessment of adulteration level in diesel fuels.

Flash Point in ${ }^{\circ} C$ : Table 1 shows the values of flashpoints for the adulterated samples. These tests were carried out for all the adulterated fuel blends. It was possible to observe an increase in flashpoint due to the incorporation of kerosene into diesel fuel, but even with this increase, the blends remain in accordance with the specification for this parameter, where points above $38^{\circ} \mathrm{C}$ are accepted even though a small increase was observed (ANP - DOU 13.01.2017; Oliveira et al., 2017). The flash point is controlled to meet safety requirements for fuel handling and storage. In general, diesel fuel flash point varies between 52 to $96{ }^{\circ} \mathrm{C}$. The flash point obtained for the various mixtures were within the range of 48$73^{\circ} \mathrm{C}$. This value is according to UNE 590 (2013) that indicates a minimum flash point of $55{ }^{\circ} \mathrm{C}$. The Flashpoint in ${ }^{\circ} \mathrm{C}$ value changed as more kerosene was added to the diesel fuel. The diesel fuel finally lost its suitability completely in the ratio of diesel to kerosene at a mixture of $35: 65$ whose value was $52^{\circ} \mathrm{C}$. A sharp reduction from $57{ }^{\circ} \mathrm{C}$ at the proportion of $40: 60$ in Table 1. The difference also seems to provide evidence that there is no systematic procedure for the adulterations of diesel fuel among the manufacturers. Moreover, this situation together with the common usage would also bring about accidents or cause explosions in public buses and loss of lives, which is frequently stated in national media (Y. Uzun, 
2014).With the correlation coefficient $\left(\mathrm{R}^{2}\right)$ of 0.9984 and analyses of variance value of $\operatorname{Pr}>F<0.0001$, a flash point can be a suitable parameter for assessment of adulteration level in diesel fuels.

Kinematic Viscosity at $37.8{ }^{\circ} \mathrm{C}$ : The kinematic viscosity is a parameter influencing the emission of pollutants. Furthermore, it affects the qualities required for lubrication since it indicates the liquid resistance to flow. Thus, diesel fuel with a high value of kinematic viscosity does not flow easily causing engine or fuel system damage. Whereas a diesel fuel with low kinematic viscosity value may not provide adequate lubrication to plungers, barrels and injectors. The kinematic viscosity of diesel fuel is normally specified at $40^{\circ} \mathrm{C}$ and fuels with Kinematic viscosities over $4.5 \mathrm{~mm}^{2} / \mathrm{s}$ at $40{ }^{\circ} \mathrm{C}$ are not suitable to be used in diesel engines. The UNE 590 (2013) indicates a kinematic viscosity range of $2.00-4.50 \mathrm{~mm}^{2} / \mathrm{s}$. It can be seen in Table 1, the kinematic viscosity range from $1.5-3.5 \mathrm{~mm}^{2} / \mathrm{s}$. Also, it can be observed that mixtures with high kerosene additives show higher kinematic viscosity values. The values obtained were in agreement with the work done by Sh. R. Yadav et al., 2005 when they compared the density and kinematic viscosity of fuels (diesel and kerosene) with respect to variations in opacity on the effect of adulteration on diesel with kerosene. Furthermore, the correlation coefficient $\left(\mathrm{R}^{2}\right)$ was 0.9962 and analyses of variance gave a $\operatorname{Pr}>\mathrm{F}<0.0001$. Compared to the density test, kinematic viscosity test was a better indicator for assessment of adulteration level. An intrinsic intensity modulated fibre optic sensor for determining adulteration of petrol and diesel by kerosene as reported (Sukhdev, 2002).

Conclusion: From means values, the graphs, the correlation coefficients and ANOVA values, it shows clearly that diesel fuel adulteration has an effect on flash point, distillation, kinematic viscosity and the density. The results showed a considerable level of adulteration of diesel with kerosene. This high level of kerosene contain appreciable quantities of sulphur that leads to the release of $\mathrm{NO}_{\mathrm{x}}$ and $\mathrm{SO}_{\mathrm{x}}$ gases which are harmful to the atmosphere in Ghana. Also, the amount of kerosene found in diesel fuels in Ghana leads to rapid degradation of diesel engines compared to those found in advance countries such as Europe. However, from certain mixture of diesel and kerosene downwards are not acceptable for use at all. It is therefore recommended that further analysis should be conducted using other highly sensitive methods. For example, the use of Biocode markers for a spot check, excitation-emission matrix spectral subtraction fluorescence, opacity value and enforcing regulatory bodies to periodically assess the level of adulteration to minimize health hazards as a result of vehicular emissions.

\section{REFERENCES}

ANP - Agência Nacional do Petróleo, Gás Natural e Biocombustíveis (2017); Resolução No. 30 de 23.12.2013 - DOU 13.01.

ASTM D 86 (2012). Standard Test Method for Distillation of Petroleum Products at atmospheric pressure. ASTM International: West Conshohocken, PA.U.S.A.

ASTM D445-15, 2015. Standard Test Method for Kinematic Viscosity of Transparent and Opaque Liquids (and Calculation of Dynamic Viscosity). ASTM International: West Conshohocken, PA, U.S.A.

ASTM Standard D1298 (2004). Standard Test Method for Density, Relative Density, or API Gravity of Crude Petroleum and Liquid Petroleum Products by Hydrometer Method; ASTM International: West Conshohocken, PA.U.S.A.

ASTM Standard D2270 (2004). Standard Practice for Calculating Viscosity Index from Kinematic Viscosity at $40{ }^{\circ} \mathrm{C}$ and $100{ }^{\circ} \mathrm{C}$; ASTM International: West Conshohocken, PA, U.S.A.

ASTM Standard D92 (2004). Standard Test Method for Flash and Fire Points by Cleveland Open Cup Tester; ASTM International: West Conshohocken, PA, U.S.A.

Brown, E (2016). Characterization and differentiation of chemical fingerprints of virgin and used lubricating oils for identification of contamination or adulteration sources, Fuel. 163.271-281

Danyelle, AC; Luis, AC; Eustáquio, VRC; Lucio, LB (2019). Application of time-domain NMR as a methodology to quantify adulteration of diesel fuel with soybean oil and frying oil, Fuel, Vol. 252.567-573,

Dzida, M., Prusakiewicz, P., (2008). The effect of temperature and pressure on the physicochemical properties of petroleum diesel oil and biodiesel fuel. Fuel.1941-1948

Gambarra NFF., Marino G., Araújo MCU., Galvão $\mathrm{RKH}$, Pontes MJC, de Medeiros EP, et al. Classification of edible vegetable oils using square wave voltammetry with multivariate data analysis. Talanta. 77:1660-6. 
Graham Hill and John Holman, (2000). Chemistry in Context, $5^{\text {th }}$ edition, Nelson \& Sons Ltd., Plymouth, UK. pp. 397-399.GS/PAS 1(2005).

Henry Mensah-Brown (2013). Optimization of the production of lubricating oil from re-refined used lubricating oil using response surface methodology; ARPN J. Engineer. 8 (9), pp. 749756

Jonah, SA, Umar, I M, (2004). Estimating adulteration of petroleum-based fuels using neutron reflectometry technique, Radiation Physics and Chemistry. Rad. Physic. Chem. 71: 889-890

Kadir G., and Yasin U., (2015). Characterization of the properties of diesel-based oil-solventwaste oil blends used as generic fuel in diesel engines, Fuel Processing Technol. 139: 135-141

Kun LT., Wenming Y., Balaji, M., Dezhi Z., Wenbin Y., Feiyang Z.(2017). Development of reduced kerosene-diesel reaction mechanism with embedded soot chemistry for diesel engines, Fuel xxx (2016) Xxx-Xxx, http://dx.doi.org/10.1016/j.fuel.2016.05.029

Maceiras, R.; Alfonsín, V.; Morales, FJ. (2017). Recycling of waste engine oil for diesel production, Waste Management. 60, 351-356

Oliveira FM, Carvalho LS, Teixeira LSG, Fontes CH, Lima KMG, Câmara ABF, (2017). Predicting cetane index, flash point and content sulfur of diesel-biodiesel blend using an artificial neural network model. Energy Fuels; 31(4), 3913-3920

Predojevic, Z., (2008). The production of biodiesel from waste frying oils: a comparison of different purification steps. Fuel, pp.3522-3528.UNE EN ISO 3838, (2004). Crude Petroleum and Liquid or Solid Petroleum Products. Determination of Density or Relative Density. Capillary-Stoppered Pycnometer and Graduated Bicapillary Pycnometer Methods
Sukhdev, R., (2002).Fibre optic sensor for determining adulteration of petrol and diesel by kerosene. Science Direct: Sensors and Actuators B: Chemical, 55 (23): 212-216.

UNE-EN 590, (2013). Automotive Fuels. Diesel. Requirements and Test Methods

USEPA regulations at 40CFR 79 (2017).United States Environmental Protection Agency, Office of Air and Radiation, Office of Transportation and Air Quality, Transportation and Regional Programs Division (Mail Code 6406J), Washington, DC 20460-0001

Uzun, Y. (2014). Investigation of Some Physicochemical Properties of Number 10 Lubes in Relation to Their Environmental Impact Potential, Department of Environmental Engineering, Akdeniz University, Antalya,

Wemming Y., Kun LT., Kah WK. (2017). Impact of Various Factors on the Performance and Emissions of Diesel Engine Fueled by Kerosene and Its Blend with Diesel, Energy Procedia, 142: 1564-1569

Yadav, ShR., Murthy KV, Mishra, D. and Baral, B. (2005). Estimation of petrol and diesel adulteration with kerosene and assessment of the usefulness of selected automobile fuel quality test parameters, Inter. J. Environ. Sci. Technol.1 (4), 253-255.

Yang, C., Yang, Z., Zhang, G., Hollebone, B., Landriault, M., Wang, Z., Patrick Lambert, Brown, CE.,(2016). Characterization and differentiation of chemical fingerprints of virgin and used lubricating oils for identification of contamination or adulteration sources, Fuel, 163, pp. 271-281 